\title{
Chronobiological Aspects of Impact of Apnoic Episode and Reoxygenation on the Electrical Myocardial Properties and Autonomic Nervous System Activity in Wistar Rats
}

\author{
Pavol Svorc, Ivana Bacova, Pavol Svorc, Jr., \\ Monika Novakova and Alexander Marossy \\ Additional information is available at the end of the chapter
}

http://dx.doi.org/10.5772/57168

\section{Introduction}

The most commonly diagnosed sleep disordered breathing is obstructive (OSA) and central (CSA) sleep apnea. However, establishing the pathogenic mechanisms are not clear and precise contribution of OSA or CSA in the development of cardiovascular disease is not fully understood (Arias and Sanchez, 2007). Increased sympathetic activity induced by hypoxia, blood viscosity, inflammation (Chowdhuri et al., 2007; Patel and Rosen, 2007) or increased oxidative stress (Schulz et al., 2006) may mediate establishing pathogenesis. In both of these disorders are described serious complications significantly increasing the risk of arterial hypertension, coronary heart disease, heart rhythm disorders, including myocardial infarction. Similarly, CSA is accompanied by a variety of disorders of the heart, such as right ventricular dysfunction (afterload) (Bugress, 1998).

Apnea episodes produce not only short-term systemic hypoxia as well as hypercapnia and acidosis, where not only the myocardium is suffering disorders (Budhiraja and Quan, 2005; Schulz et al., 2006; Aronow, 2007; Patel and Rosen, 2007; Arias and Sanchez, 2007), but also the central nervous system. These clinical trials unambiguously ascribe the increased risk of cardiac events to apneic episodes occuring during sleep. In addition, respiratory alkalosis is also an extremely common and complicated problem affecting virtually every organ system in the body, the etiology of which may be related to pulmonary or extrapulmonary factors. However, not at all consider the effect of the recovery of oxygen delivery (reoxygenation) after 
apneic episodes on the onset or development of ventricular arrhythmias. Reoxygenation after apneic episodes does not automatically normalize myocardial properties (electrophysiological and mechanical), but can also increase the risk of reoxygenation arrhythmias (Mubagwa et al., 1997; Shinmura et al., 1997). There are many cardiac effects of pulmonary hyperventilationinduced respiratory alkalosis including tachycardia, heart rhythm disorders (Foster et al., 2001) and supraventricular tachycardia caused by altered atrioventricular nodal conduction (Chen et al., 2001). Disorders of pulmonary ventilation are clearly considered to be proarrhythmogenic.

The timing of the transient risk state is dependent upon the synchronisation of the patient and not upon the time per se. After a transmeridian flight over several time zones, individuals will be out of phase for at least a short duration of time with their new surroundings. Information on the speed of the adjustment of the human circadian system is not available, but the system is probably in a transient state of internal desynchronisation for several days, depending on the magnitude of the longitudinal transmeridian displacement. It is commonly stated that it takes one day for every change in meridian. In shift workers, the degree of disturbance of circadian desynchronisation of physiological functions is in relation to its surroundings and may vary with the type of working hour shift. Also, the interaction of endogenous rhythms with environmental factors must be considered.

\section{Chronobiology of the electrophysiological myocardial properties under apnoic episode and reoxygenation}

It has been shown that all cardiac functions as well as the symptoms of cardiovascular diseases, including the various types of ventricular arrhythmias, morbidity and mortality, show circadian dependence (rhythmicity (Henry et al., 1990; Gilpin et al., 1990; Waterhouse et al., 2000). Knowledge regarding circadian variations of the electrophysiological myocardial properties of the heart and autonomic nervous system activity may help to more precisely evaluate the risk of ventricular arrhythmia incidence. The evidence in the literature regarding circadian patterns in arrhythmias is complicated by the fact that nearly all of the studies are confounded by a variety of factors independent of the intrinsic arrhythmogenic activity (Portaluppi and Hermida, 2007).

But, the circadian system is the foundation of the sleep-wake cycle, disorders and abnormalities in sleep are often connected with disorders or abnormalities in the circadian system. Circadian rhythm sleep disorders, such as jet lag syndrome (Auger and Morgenthaler, 2009) and shift work sleep disorder (Akerstedt and Wright, 2009), are those specifically attributed to dysfunctions or insufficiencies in the circadian system. Taking into consideration the preeminence of the circadian clock in timing sleep, it is likely that other sleep disorders are also linked to circadian system abnormalities (Richardson, 2005).

There are the clinical trials, which refer to fact that connection of the circadian rhythmicity of the cardiovascular events with apnoic episodes may have practical relevance in screening for patients with OSA and may have prognostic clinical value in predicting future cardiovascular 
events. The risk of sudden death from cardiac causes has peak from 06:00h to noon and a nadir from midnight to $06: 00 \mathrm{~h}$. OSA is associated with neurohormonal and electrophysiological abnormalities that may increase the risk of sudden death from cardiac causes, especially during sleep. Gami et al. (2005) followed this dependence in 112 people, who died suddenly from cardiac causes. They found that from midnight to $06: 00 \mathrm{~h}$, sudden death from cardiac causes occurred in $46 \%$ of people with OSA, as compared with $21 \%$ of people without OSA. People with sudden death from cardiac causes from midnight to $06: 00 \mathrm{~h}$ had a significantly higher apnea-hypopnea index than those with sudden death from cardiac causes during other intervals, and the apnea-hyponea index correlated directly with the relative risk of sudden death from cardiac causes from midnight to 06:00h. Thus, people with OSA have a peak in sudden death from cardiac causes during the sleeping hours, which contrasts strikingly with the nadir of sudden death from cardiac causes during this period in people without OSA. The different variation in onset of myocardial infarction was found in patients with and without OSA. Myocardial infarction occurred between 12:00h and 06:00h in 32\% of OSA patients and $7 \%$ of non/OSA patients. Of all patients having myocardial infarction between 12:00h and 06:00h, 91\% had OSA. These findings suggest that OSA may be a trigger for myocardial infarction and patients having nocturnal onset of myoacardial infarction should be evaluated for OSA. Future research should address the effects of OSA therapy for prevention of nocturnal cardiac events (Kuniyoshi et al., 2008).

Besides humans, almost all animals are exposed to periodic repetitions of light and dark cycles during a 24-hour (circadian) period to which virtually all physiological functions are synchronized. Disturbance of the internal synchronization of rhythms with the periodicity of the external environment may manifest by increased susceptibility to disease. Surprisingly, there are only few works describing day-time of the experiment running or synchronization of animals to the external environmental periodicity, such as the light-dark (LD) cycle. It can be a problem, because the LD cycle is given for one of the strongest circadian synchronizators of the animal endogenous rhythms. Therefore, the creation of experimental, in vivo, chronobiological animal models may help reveal some of the relationships between circadian time and biological function, which is sometimes very difficult to study in humans. From this reason, the circadian variability should be considered as important factor especially in the cardiovascular studies.

For example, the $24 \mathrm{~h}$ course of the myocardial vulnerability showed the highest susceptibility of the rat ventricular myocardium to arrhythmias between 12:00h and 15:00h and highest resistance between 24:00h and 03:00h under normooxic conditions (Svorc et al., 1994; 2012). In hypoventilatory rat model, hypoventilation-induced systemic hypoxia, hypercapnia and acidosis increased the myocardial vulnerability and decreased heart rate values throughout the 24-hour period. Circadian rhythm of the electrical stability of the heart was changed to biphasic with smaller peak between 15:00h and 18:00h and higher peak between 24:00 h and 03:00h. The hypoventilatory circadian rhythm of the electrical stability of the heart was not significant as revealed by the population mean cosinor (Svorc et al., 1997, 2000). Hyperventilation does not disturb, but likely only modifies the circadian rhythm of the electrical stability of the heart. The hyperventilatory $24 \mathrm{~h}$ rhythm of the myocardial vulnerability shows a 
nonsignificant pattern, with higher myocardial resistance during the dark (active) period of the LD cycle.

On the basis of these facts, it is clear that the disorders of pulmonary ventilation (hypoventilation, hyperventilation) not only change the electrophysiological properties of the myocardium, but also circadian rhythm of the myocardial vulnerability to the ventricular arhythmias. This includes also apnoic episodes, which are also arrhythmogenicly. Problems of connection of the circadian rhythmicity of the cardiovascular system with apnoic episodes is not study in more detail, although clinical studies suggest a connection between sudden death from cardiac causes and OSA dependent on circadian timing. The question remains whether there also a reverse connection? Could patients with OSA, without obvious cardiac diseases, be more susceptible to heart-rhythm disorders during sleep after a change in synchronisation with local time? We evaluated if apneic episodes and subsequent reoxygenation changed the electrical predisposition of the heart to ventricular arrhythmias, heart rate (HR), activity of the autonomic nervous system and acid-base balance by the same manner in active (dark) and nonactive (light) part of the day.

The present study conformed with the Guide for the Care and Use of Laboratory Animals published by the US National Institutes of Health (NIH publication number 85-23, revised 1996). The study protocol was also approved by the Ethics Committee of the Medical Faculty of Safarik University (Kosice, Slovak Republic) (permission number 2/05).

The experiments were performed in ketamine/xylazine anaesthetized female Wistar rats (ketamine [Narkamon] $100 \mathrm{mg} / \mathrm{kg}$ [SPOFA Prague] + xylazine [Rometar] $15 \mathrm{mg} / \mathrm{kg}$, intramuscularly). Anaesthesia was maintained at a level such that painful stimuli and surgery did not evoke noticeable motor or cardiovascular responses. On completion of the experiments, rats were sacrificed by cardiac administration of an overdose of ketamine. The effect of the light period (light phase) on electrophysiological properties of the heart, acid-base balance, ions and heart rate variability (HRV) were followed after adaptation to an LD cycle (12h light, $12 \mathrm{~h}$ dark, $40 \%-60 \%$ humidity, room temperature $24{ }^{\circ} \mathrm{C}$, two animals/cage with access to food and water ad libitum) for four weeks, with the dark part of the cycle from 18:00h to 06:00h. The effect of the dark period (dark phase) was followed after adaptation to the inverse setting of the LD cycle (12h dark, $12 \mathrm{~h}$ light), with the dark period from 06:00h to 18:00h. The experiments were performed twice (the first animal between 09:00h and 10:00h and the second animal between 12:00h and 13:00h) (scheme 1).

\subsection{Ventilation}

The trachea was exposed at the mid-cervical level and cannulated using a plastic tube. A tracheal cannula was attached to a volume-rate-regulated artificial ventilator (UGO Basile, Comerio-Varese, Italy) and animals ventilated by room air. The parameters of the initial ventilation and reoxygenation were a respiratory rate of 50 breaths/min and a tidal volume of $1 \mathrm{ml} / 100 \mathrm{~g}$ body weight. The parameters of ventilation were chosen on the basis of validated methods of artificial controlled ventilation using room air for pentobarbital-anaesthetised rats, which can be applied for the preservation of normal acid-base balance. Apneic episode was simulated by switching off the ventilator for $2 \mathrm{~min}$. The respiratory effect of the pulmonary 


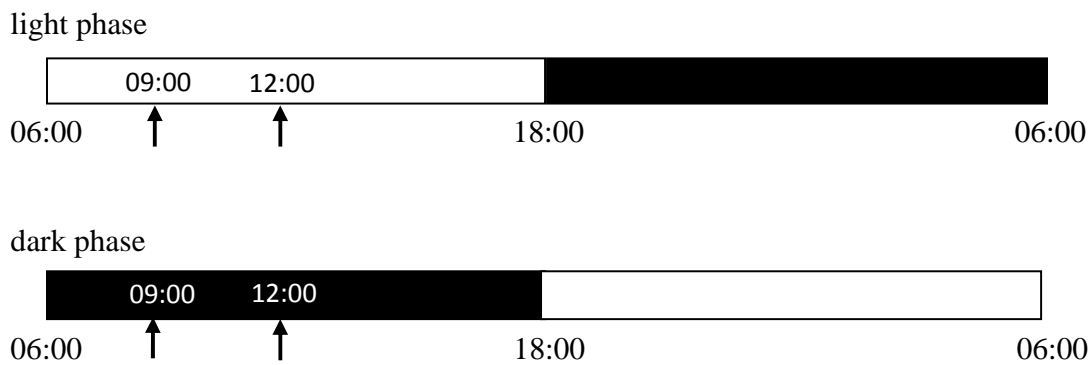

Scheme 1. Adaptation of rats to the LD cycle $(12 \mathrm{~h}: 12 \mathrm{~h})$ in a special room. Light stripe - the light part of the rat regime day, dark stripe - the dark part of the rat regime day. Arrows indicate the time of the experiment running.

\begin{tabular}{|c|c|c|c|c|c|c|}
\hline Intact & stabil: & 4pone & 5 reoxy & 10 reoxy & 15 reoxy & 20 reoxy \\
\hline
\end{tabular}

Scheme 2. Experimental protocol. Arrows denote single steps of the experiment with measurement of the ventricular arrhythmia threshold for evaluation of the electrical stability of the heart.

ventilatory changes was monitored by the analysis of the acid-base balance from blood samples taken from the femoral artery unrepeatedly at the end of experiment in the single groups.

\subsection{Experimental protocol}

Animals were randomly divided into seven groups (14 animals in each group) for the light and dark parts of the day to evaluate the acid-base balance in single experimental steps. Group 1 contained intact rats before surgical interventions, spontaneous breathing under ketamine/ xylazine anaesthesia (Intact). Group 2 contained rats after tracheotomy, thoracotomy and 5 min of normal artificial ventilation (Stabil). Group 3 contained rats who underwent 2 min of apnoea (Apnoea). Group 4 had rats that underwent 5 min of reoxygenation (5 reoxy). Group 5 had rats that underwent 10 min of reoxygenation (10 reoxy). Group 6 involved rats who had $15 \mathrm{~min}$ of reoxygenation (15 reoxy). Group 7 contained animals that had $20 \mathrm{~min}$ of reoxyge nation (20 reoxy) after $2 \mathrm{~min}$. apneic episode. The experiment was completed by taking blood samples (scheme 2).

\subsection{Measurements}

ECG parameters, acid-base balance and HRV measurements were performed in the supine position on a preheated table. Body temperature was maintained at a level equivalent to the rectal temperature measured before anaesthetic agent administration. Heat provided by an infrared lamp was used to prevent any hypothermic effects on heart rate.

The chest was opened via a parasternal thoracotomy for elimination of nervous breathing control mechanisms and measurement of the electrical stability of the heart (measured by the ventricular arrhythmia threshold - VAT). The VAT was estimated as the minimal amount of 
electrical current $(\mathrm{mA})$ needed for elicitation of ventricular arrhythmias. The heart was protected from changes in temperature and humidity by administering physiological solution, dropwise, to the heart, with temperature equal to rectal temperature measured before the anaesthetic agent application. The stimulating platinum electrodes (diameter $1 \mathrm{~mm}$ and $5 \mathrm{~mm}$ interelectrode distance, temperatura equal to rectal temperature) were placed at the base of right ventricle. Parameters of the electrical stimulation were $400 \mathrm{~ms}$ series of rectangular pulses; frequency, $30 \mathrm{~Hz}$; impulse length, $10 \mathrm{~ms}$ ). Stimuli were triggered by onset of the $\mathrm{R}$ wave in the II lead of electrocardiography (ECG) on the base of synchronization of ECG with stimulator. The current intensity was increased progressively by increments of $0.2 \mathrm{~mA}$ until ventricular arrhythmias were obtained. Recovery of the sinus rhythm was spontaneous.

The bipolar electrodes were attached to the upper and lower limbs and served for recording of the heart rate (HR), ECG and heart rate variability (HRV). ECG was further analysed using computer software (ECG Practic Veterinary, Prague, Czech Republic). Measurement of the ECG and HR (mean value of the last four cycles) were carried out: in intact animals; after tracheotomy (Tr); thoracotomy (To); after each minute of the 5-min stabilization; after each 30 s of the apneic episode; and after each minute of the 20-min reoxygenation. HRV was analysed from ECG using computer software (Varia Pulse TF4, Sima, Olomouc, Czech Republic). Analysis of HRV was performed by scoring 600 RR intervals needed for calculation of HRV parameters. The following HRV parameters were measured: RR interval duration (ms), very low frequency (VLF) power (corresponding to sympathetic activity), low frequency (LF) power (baroreceptor activity, or sympathetic and parasympathetic activity together), high-frequency (HF) power (corresponding to parasympathetic activity) $\left(\mathrm{ms}^{2}\right)$ and relative VLF power, relative LF power and relative HF power (\%).

\subsection{Statistical analysis}

The data are presented as the means \pm SD. A non-paired $t$ - test was used for statistical evaluation. Differences of $p<0,05$ were considered significant. The relationship between the evaluated parameters was determined by calculating correlation coefficients. The interval $-0,4$ $>\mathrm{r}>+0,4$ was considered to be significant. The data were processed from trials that were conducted independent of the season because circannual variation can also occur in the parameters that were examined.

\subsection{Limitations of study}

Absence of the reference ECG values, acid-base balance parameters and HRV parameters (also literary current data) from animals without anaesthesia and in the LD dependence can be a limitation in our study. The next limitation can be a relatively large dispersion of the measured values. The ECG, acid-base and HRV values showed intra- and interindividual variability, which is a problem, mainly concerning in vivo studies. The discrepancy can be explained by the production of spontaneous, unpredictible alterations in the electrophysiologic properties of the heart induced by anaesthesia, or hormonal and homeostatic reflexes in the animals. The third limitation was that rats were in systemic asphyxia from the start to the end of the experiment independent of the LD cycle. This state has been described by other authors in rats 
(Sumitra et al., 2004; Alva et al., 2006) and reflects the changes in cardiovascular (Sumitra et al., 2004) and respiratory (Farver et al., 1986) systems.

In the first moment, we have focused on the assessment of the changes in heart rate and electrical stability of the heart. The disruptive effect of acute hypoxia on the LD-dependent differences in the HR-response curve was not confirmed, as suggested by other authors (Mortola and Seifert, 2000; Bishop et al., 2001; Bosco et al., 2003; Kaplan et al., 2003; Mortola, 2007). However, it is known that ketamine/xylazine anaesthesia decreases heart rate (Hsu et al., 1986; Morita et al., 1997; Cope et al., 1997) which has been connected with systemic asphyxia after administration of anaesthetic agent (Švorc et al., 2009).

One of the main conclusions is that the HR was significantly and systematically higher in the dark part than in the light part of the day during apneic episode-induced acute systemic asphyxia. Start of apneic episode significantly $(p<0,001)$ decreased the HR only in the dark part of the day compared with the HR value from the end of the period of stabilization, not in the light part. The HR decreased gradually until the end of the apneic episode in both lighted parts of the day. Although reoxygenation significantly $(p<0,001)$ increased the HR in both lighted parts of the day, surprising was the finding that the LD differences were eliminated during reoxygenation.

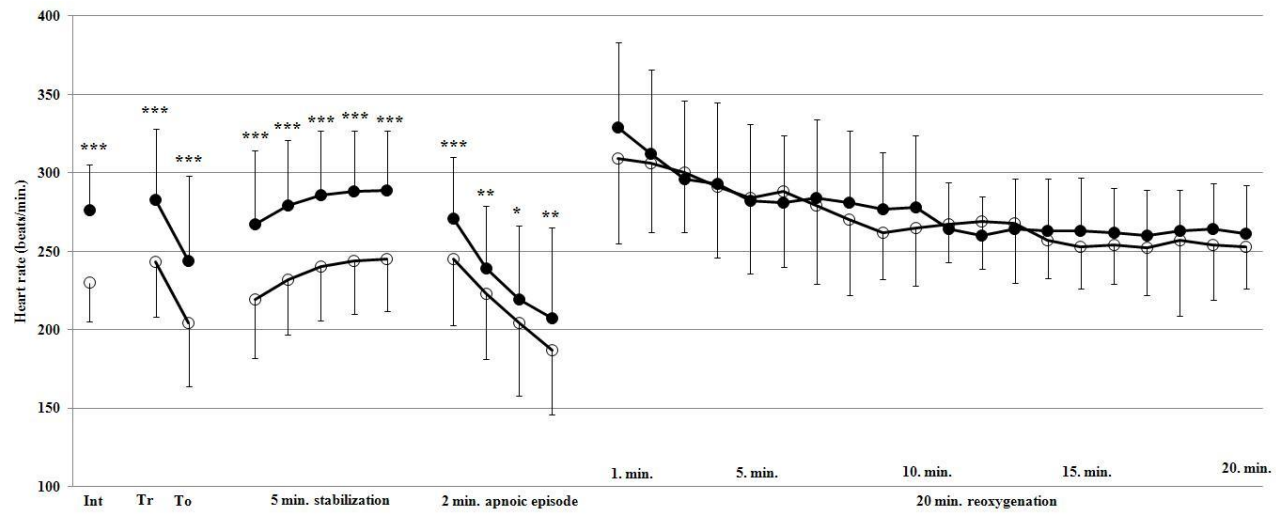

Figure 1. HR changes in single experimental steps. White circles represent the light part of the day and black circles the dark part. Int: intact animals under ketamine/xylazine anaesthesia before surgical intervention allowing for spontaneous breathing in the supine position. Tr: tracheotomy. To: thoracotomy. ${ }^{* *} p<0,001 ;{ }^{* *} p<0,01{ }^{*} p<0,05$ statistically significant HR differences between the light and dark part of the day (Svorc Jr. et al., 2011).

Twenty minutes of reoxygenation recovered the HR approximately to the HR levels of spontaneously breathing animals. Decrease of HR can be explained by effect of hypoxia (Hinojosa-Laborde and Mifflin, 2005) or a larger parasympathetic influence (Hayashida et al., 1996; Svorc Jr. et al. 2013) (figure 1).

The electrical stability of the heart after the period of stabilization showed significant $(p<0,001)$ LD differences with the higher values during the active (dark) part of the regimen day. Apneic 
episodes significantly $(\mathrm{p}<0,001)$ decreased the VAT in both light parts of the day and eliminated LD differences. The results clearly demonstrate and confirm the pro-arrhythmogenic effects of apneic episodes (Budhiraja and Quan, 2005; Schulz et al., 2006; Aronow, 2007; Patel and Rosen, 2007; Arias and Sanchez, 2007). In our model, we initially stated that the pro-arrhythmogenic effects of apneic episodes act in the same manner regardless of whether they are in the light (non-active) or dark (active) part of the day for rats (figure 2).

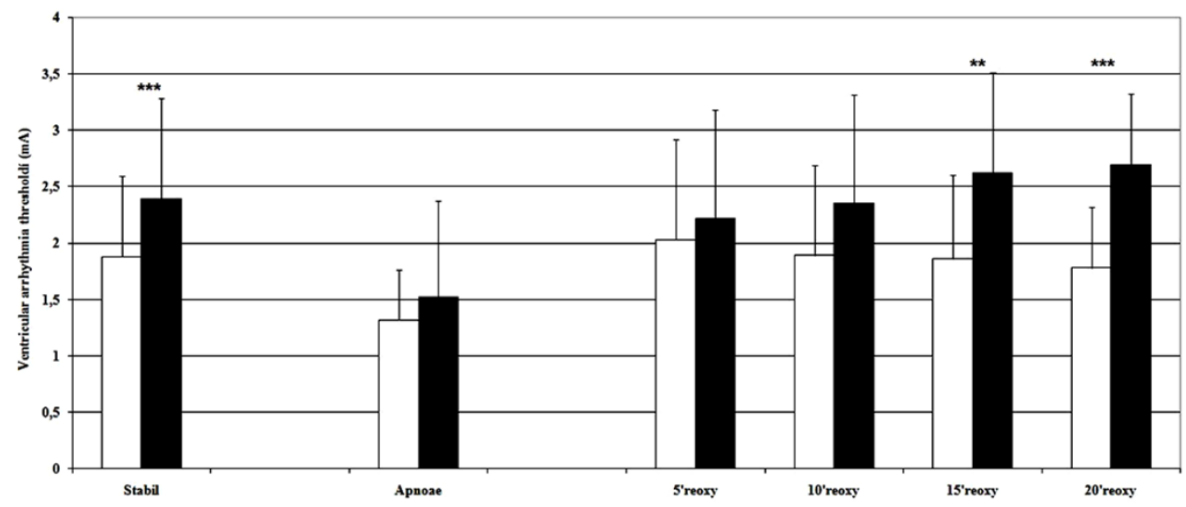

Figure 2. VAT changes in single experimental steps. White columns represent the light part of the day, and black columns the dark part. Stabil: animals after tracheotomy, toracotomy and 5 min artificial ventilation. Apnoae: after a $2-$ min apneic episode. 5 reoxy, 10 reoxy, 15 reoxy and 20 reoxy: after 5, 10, 15 and 20 min of reoxygenation, respectively. ${ }^{* * *} p<0,001 ;{ }^{* *} p<0,01$ statistically significant VAT differences between the light and dark part of the day (Svorc Jr. et al., 2011).

The decreased the electrical stability of the heart also in the course of whole $24 \mathrm{~h}$ period (Svorc et al., 1994, 1997) confirm results from other electrophysological studies about the effect of hypoxia on myocardium. The reason of disorders of the heart rhythm in the hypoxic state is a sudden increase of the extracellular $\mathrm{K}^{+}$concentration, which play the crucial role in the changes of the rest membrane potential and can produce the ectopic activity as well as inhibition of the rapid reaction (Opie et al., 1979). The rapid increase of the extracellular $\mathrm{K}^{+}$concentration is result of $\mathrm{K}_{\mathrm{ATP}}$ channel activation. It is inactivated in the normooxic conditions, but it is activated in the hypoxic or anoxic conditions (Noma and Shibasaki, 1985; Sanguinetti et al., 1988; Daut et al., 1990; Billman et al., 1993). Thus, the blockade of $\mathrm{K}_{\text {ATP }}$ channels acts antiarrhythmic (Wolleben et al., 1989). We can suppose that mechanism of the $\mathrm{K}^{+}$current activation by hypoxia can be responsible for change in the electrical stability of the heart also in the circadian dependence, although biphasic course of the VAT is not perspicuously explained by this mechanism.

However, it seems that recovery of the pulmonary ventilation after apneic episodes can also contribute to heart rhythm disorders, but this is dependent upon the light (non-active)-dark (active) cycle. In the dark part of the day, the gradual increase in the VAT is associated with the duration of reoxygenation (anti-arrhythmogenic effect) compared with the light part of the 
day, where the contrary tendency was observed (pro-arrhythmogenic effect). This suggests that synchronisation of the organism to a particular enviromental periodicity could be a crucial factor influencing myocardial vulnerability to ventricular arrhythmias mainly in the process of recovery of the pulmonary ventilation after an apneic episode. Our model suggests that synchronisation to local time may be an important factor for evaluation of cardiovascular risk in patients suffering from OSA. Analyses of myocardial reactions to acute systemic asphyxia induced by apneic episodes (as well as to reoxygenation) is very important in experimental respirology and cardiology because the myocardium reacts differently depending on the external environmental periodicity.

\section{Chronobiology of the ECG parameters during apnoic episode and reoxygenation}

Therefore, myocardial vulnerability changes depend on the breathing as well as on the lighted mode of the rat regime day. In addition, number of electrophysiological properties of the cardiac structures are recognized as essential for the triggering and maintenance of heart rhythm disorders and show dependence on the time of day (Portaluppi and Hermida, 2007). The question remains, which electrophysiological properties play a role in the myocardial sensitivity to the ventricular arrhythmias during apnoic episode and recovery of the pulmonary ventilation (reoxygenation) depending on the cycle of the light and the darkness succession. Ventilatory disorders act arrhythmogenicly and the chronophysiological view on the functional interconnection between disorders of pulmonary ventilation and changes in the electrophysiologic properties of the heart are also important. We got from the fact that ventricular arrhythmias may arise either from the disorders of the impulse formation and conduction (presented by PQ interval), or from a enlarged dispersion of the refractory periods (presented by QT interval).

We analyzed the PQ and QT interval changes (Bacova et al., 2010) in the single experimental steps. In intact animals, higher values of PQ interval duration during in the light (inactive, sleep) phase of the rat regime day suggest that ventricular myocardium is more susceptible to arrhythmias originating from impulse production and conduction compare to the active part of the day. The speed of the impulse conduction from atria to ventricles (PQ interval) depends from action potential amplitude, reflecting the active role of $\mathrm{Na}^{+}$channels (Carmeliet, 1986; Amitzur et al., 2000). It can mean that ketamine/xylazine anaesthesia with associated systemic asphyxia as well as with subsequent surgical interventions do not affect the kinetics of the $\mathrm{Na}$ ${ }^{+}$channels, which are likely to be different in the light and dark part of the rat regime day. It seems that PQ interval is the relative stable electrophysiological parameter of the heart and it is directly influenced by the LD cycle (figure 3). Mechanisms of such different effect of ketamine/xylazine anaesthesia are still unknown and were not analyzed in detail.

Apneic episodes, obstructive or central, often in a connection with the sleep apnea syndrome, are linked with disorders of the cardiac rhythm (Cutler et. al., 2002; Yamashita et al., 2004; Bounhoure et al., 2005; Dunai et al., 2006; Bayram and Diker, 2008; Grešová et al., 2009). In our 


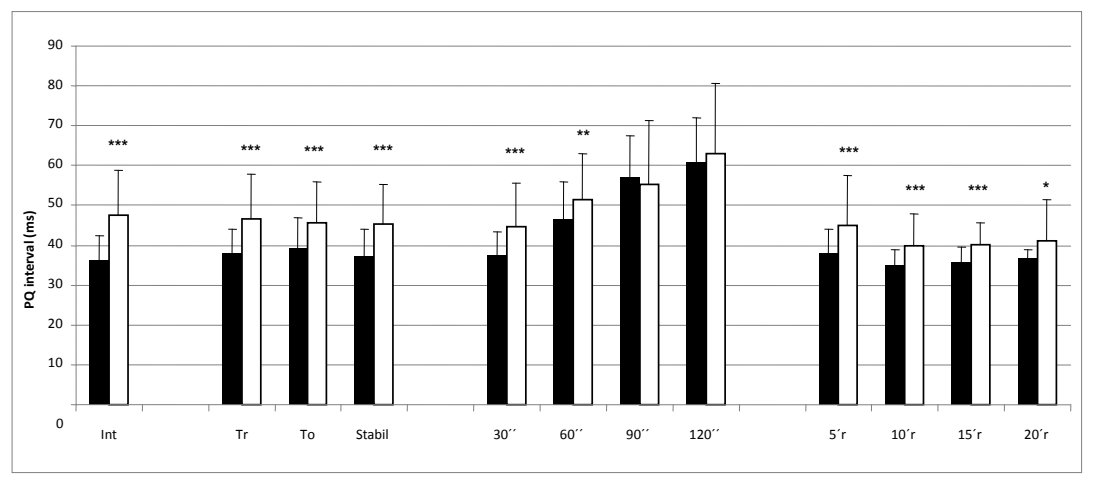

Figure 3. Mean \pm SD values of the $P Q$ interval duration in intact animals (Int), after tracheotomy (Tr), thoracotomy (To), 5 min. stabilization (Stabil), in each $30 \mathrm{sec}$. of 2 minutes apneic episode and after 5., 10., 15. and 20 minute of artificial reoxygenation.. Empty and black columns refer to light and dark parts of the day, respectively. The level of significance of differences between the light and dark part of the rat regime day is indicated by the symbol (* $p<0,05$, ** $p<0,01,{ }^{* *} p<0,001$ ) (Bacova et al., 2010).

model, short-term asphyxia increases vulnerability to the arrhythmias originating from disorders of the impulse production and conduction more in the light (inactive) than in the dark (active) part but does not disturb LD dependence. Long-term apneic episode, connected with more serious asphyxia, henceforth prolonges PQ interval and increases vulnerability to the arrhythmias but probably independently on the LD cycle. Reoxygenation recovered PQ interval duration to the pre-asphyxic values with preservation of the LD differences observed in intact animals.

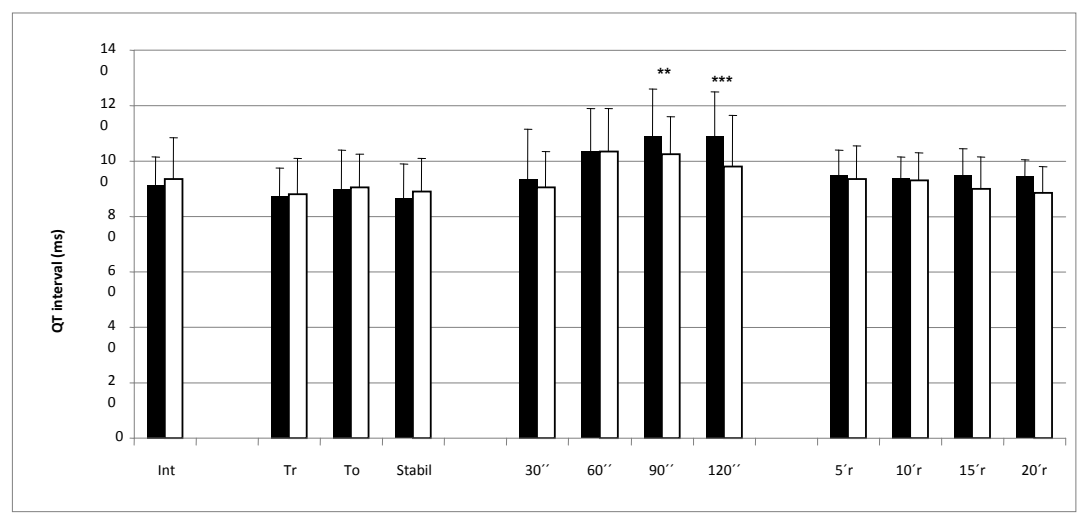

Figure 4. Mean \pm SD values of the QT interval duration in intact animals (Int), after tracheotomy (Tr), thoracotomy (To), 5 min. stabilization (Stabil), in each $30 \mathrm{sec}$. of 2 minutes apneic episode and after 5., 10., 15. and 20 minute of artificial reoxygenation. Empty and black columns refer to light and dark parts of the day, respectively. The level of significance of differences between the light and dark part of the rat regime day is indicated by the symbol $\left({ }^{*} p<0,05\right.$, ${ }^{* *} p<0,01,{ }^{* * *} p<0,001$ ) (Bacova et al., 2010). 
Loss of the LD differences in the dispersion of the refractory period durations (QT interval) can be a result of the effect of the initial asphyxia, which has distracting influence on the LD differences in QT interval. A similar situation was described by Gunes et al. (2008) in clinical study, where the loss of diurnal variation of the dispersion of the refractory periods was also present in patients having either an ischemic or non-ischemic origin of heart failure treated with optimal drug therapy. Although dispersion of the refractory period duration (QT interval) is the result of the action of more ion currents $\left(\mathrm{Ca}^{2+}, \mathrm{Na}^{+}, \mathrm{Cl}^{-}\right.$and inward rectifying $\mathrm{K}^{+}$current) (Amitzur et al., 2000), depends mainly from intracellular $\mathrm{K}^{+}$concentration (Froldi et al., 1994). This suggests that ketamine/xylazine anaesthesia together with initial asphyxia probably influence mainly $\mathrm{K}^{+}$ion current by the same manner in the both lighted parts of the day and disturb the light-dark dependence.

The opposite situation is true of the QT interval. Short-term apneic episode increased vulnerability to the arrhythmias originating from dispersion of the refractory period independently on the LD cycle, but long-term apneic episode facilitated the LD differences with the higher dispersion during the dark (active) than light (nonactive) part of the rat daily regime. The next LD difference was seen at the end of asphyxic period. Slightly decreased the QT interval duration was only during the light (nonactive) part, but not during the dark (active) one.

These changes may be caused by changes in ion channel sensitivities regarding duration and gravity of asphyxia. Hypoxia exacerbated the atrioventricular conduction by reduction of the slow inward $\mathrm{Na}^{+}$current and by rectifying $\mathrm{K}^{+}$current and depressed automaticity by the increase of the outward $\mathrm{K}^{+}$current and in the certain range by reduction of the slow inward $\mathrm{Na}^{+}$current in the isolated rabbit AV node (Nishimuraet al., 1989). Sinus interval, AH and HV interval are gradually prolonged with the duration of the hypoxia. These effects are attributed to the $\mathrm{K}^{+}{ }_{\text {ATP }}$ channel (Sawanobori 1995), which is probably activated by the endogenous adenosine released from the hypoxic myocardium ( $\mathrm{Xu}$ et al., 1994; Leone Jr. and Merrill, 1995). Our results suggest that above mentioned changes can be modified also by the LD cycle.

Interesting is fact that the average values of QT interval were slightly and nonsignicantly longer in the dark part of the day after reoxygenation compared to the light one, while the opposite tendency was observed in the intact animals and after stabilization. These slight differences probably do not have any biological significance because they may be a result of the relatively large variation in dispersion of the refractory periods, what corresponds with second limitation (Lubbe et al., 1975). Similarly, there are contrary conclusions about the effect of reoxygenation on the changes of the electrophysiological myocardial properties. Our results affirm the opinion of some authors about the antiarrhythmogenic effect of reoxygenation (Perchenet and Kreher, 1995; Bugge et al., 1997). There are papers however, which describe the serious injury of the heart by the reoxygenation (Griffiths et al., 2000; Mukai et al., 2000).

What is known about the effects of hypoxia on circadian patterns is still quite limited, especially with respect to the causative mechanistic sequence of the hypoxic effects. It appears that the most common effect of prolonged hypoxia is to decrease, and in come cases to abolish, the amplitudes of the daily oscillations, irrespective of the state of arousal or activity level. On the other hand, the evidence is that hypoxia causes only minimal and transient perturbation of the period of the rhythm. The fact that hypoxia modifies the circadian oscillations of variables as 
important as body temperature and metabolism leads to the expectation that the daily rhythms of many other functions are perturbed by hypoxia, according to their link to the primary variables (Mortola, 2007). This modification can be probably seen also in our experimental model, where the definite loss of the LD dependence was not demonstrated in followed parameters of ECG.

\section{Chronobiology and autonomic nervous system during apnoic episode and reoxygenation}

Circadian rhythms in autonomic nervous system activity are well known that directly controls circadian thythm in cardiovascular system and constitute major triggers of cardiac arrhythmias. Increased sympathetic activity accelerates heart rate, favors spontaneous depolarization, shortens the ventricular effective refractory period, and decrease the threshold for ventricular fibrillation. In contrast, increased parasympathetic activity slows heart rate, decreases AV nodal conduction, and in the presence of baseline sympathetic neural activity, increases both the ventricular refractory period and the ventricular fibrillation threshold (review of references in Portaluppi and Hermida, 2007). This direct and clear dependence, described in people and in larger experimental animals, was not confirmed in rats (Svorc et al., 1994, 1997).

OSA is associated with increased daytime and nocturnal sympathetic activity, what can be the risk factor of cardiovascular disease. It is associated with a significant worsening in heart-rate variability, heart rate turbulence and QT dynamicity parameters (Aytemir et al., 2007). Its mechanism can be explained by the observation that the sympathetic tone increases due to repetitive apneas accompanied by hypoxias and arousals during sleep. Heart rate variability representing cardiac autonomic function is mediated by respiratory sinus arrhythmia, baroreflex-related fluctuation and thermoregulation-related fluctuation. The LF/HF ratio was higher in the severe OSA syndrome group to that of the moderate group (Park et al., 2008). Structural changes occur in the airway to obstruct airflow during OSA, and the resulting apnea activates hypoxic and hypercapnic reflexes, wich in turn lead to profound elevation in sympathetic nerve activity and cyclical changes in parasympathetic nerve activity. These autonomic effects are though to contribute to the associated cardiovascular diseases (eg, hypertension) and frequently observed brady- and tachyarrhythmias (Cutler et al., 2002). Autonomic abnormalities seen in pacient with OSA include increased resting heart rate, decreased RR interval variability and increased blood pressure variability (Parish and Somers, 2004). Using heart rate variability analysis, nocturnal sinusal dysfunction contrasted with a blunted diurnal parasymathetic modulation of the sinus node. Frequent nocturnal nonsustained supraventricular tachycardias were predominantly found in patients with severe sleep related breathing disorders; however, an increased risk of ventricular arrhythmias was not found. (Roche et al., 2003).

Apneic episodes influence the autonomic nervous system activity (Aydin et al., 2004), but little is know about the effect on circadian variation in this system activities. The circadian rhythm of the LF, HF and LF/HF ratio differed significantly in the group of patients with mild OSA 
(group 2, apnea index $\mathrm{AI}>$ or $=20$ ) compared with group of patients with severe OSA (group 1 , apnea index $\mathrm{AI}<20$ ) and control group. The mean HF from 04:00h to 12:00h was significantly lower in group2 than in group1 and the control group, and it correlated significantly with the lowest nocturnal $\mathrm{O}_{2}$ saturation $(\mathrm{r}=0,58)$. The mean $\mathrm{LF} / \mathrm{HF}$ ratio during the same period was significantly higher in group2 than in group1 and the control group, and it correlated significantly with total time of the nocturnal oxygen saturation $<90 \%(r=0,64)$ and the lowest nocturnal $\mathrm{O}_{2}$ saturation $(\mathrm{r}=0,56)$. These findings suggest that sleep-disordered breathing associated with severe oxygen desaturation might influence heart rate variability not only sleep but also during daytime. OSA per se might contribute to altered circadian rhythm in autonomic activity leading to the development of cardiovascular diseases (Noda et al., 1998) also in the absence of hypertension, heart failure, or other disease states, and that it is linked to the severity of OSA (Aydin et al., 2004). These conclusions were supported by Tükek et al. (2003) in study, where examined the possible effect of diurnal variability of heart rate on the development of arrhythmias in patients with chronic obstructive pulmonary disease. They concluded that patients with chronic obstructive pulmonary disease with arrhythmia had circadian disturbances in heart rate variability such as unchanged night-time parasympathetic tone and disturbed sympathovagal balance in favour of the sympathetic system all day long, which may explain the increased frequency of arrhythmia.

The next step in the analysis of the effect of apnoic episode and reoxygenation on the electrical stability of the heart was assessment of the changes in the activity of the autonomic nervous system in LD dependence. The HRV was applied to assess these changes. HRV was not evaluated during apnoic episode because the changes in the duration of the RR intervals drastically have been extended, resulting in a high dispersion of the values.

The first 5 minutes of recovery pulmonary ventilation has been associated with significant turbulence in the heart rhythm, especially in the light part of the day (time range of R-R interval ranged from 0.025 to $\mathrm{ms} 0,717 \mathrm{~ms}$ ). In a dark part of the day, so a significant dispersion was not observed. Although the LD differences were not maintained during the 20-minute reoxygenation, in the light part has been observed nonsignificant the tendency of the shortening compare to the dark part, where the duration of the RR interval was prolonged. These results coincide with heart rate changes. Reoxygenation recovered RR interval duration to the values from intact animals only in the dark (active) part (figure 5).

Significant LD differences in power HF were seen in the intact animals with the higher value in the light part compared to the dark one. Effect of reoxygenation on the power HF has been dependent on the LD cycle. Power HF gradually increased and reached a level of intact animals with the time of the reoxygenation but only in the dark part of the rat regime day. In the light part of the day, the changes in the power HF were nesignificant and fluctuated randomly, without any tendency of decrease or increase. Significant LD differences were maintained throughout the period of reoxygenation, up to the 20th minute, where the elimination of this difference has been observed. In each interval evaluation of power HF, the value was higher in the dark compare to light part of the day (figure 6). Reoxygenation did not recover power $\mathrm{HF}$, but preserved the dominant position of the parasympathetic division in the both lighted periods. 


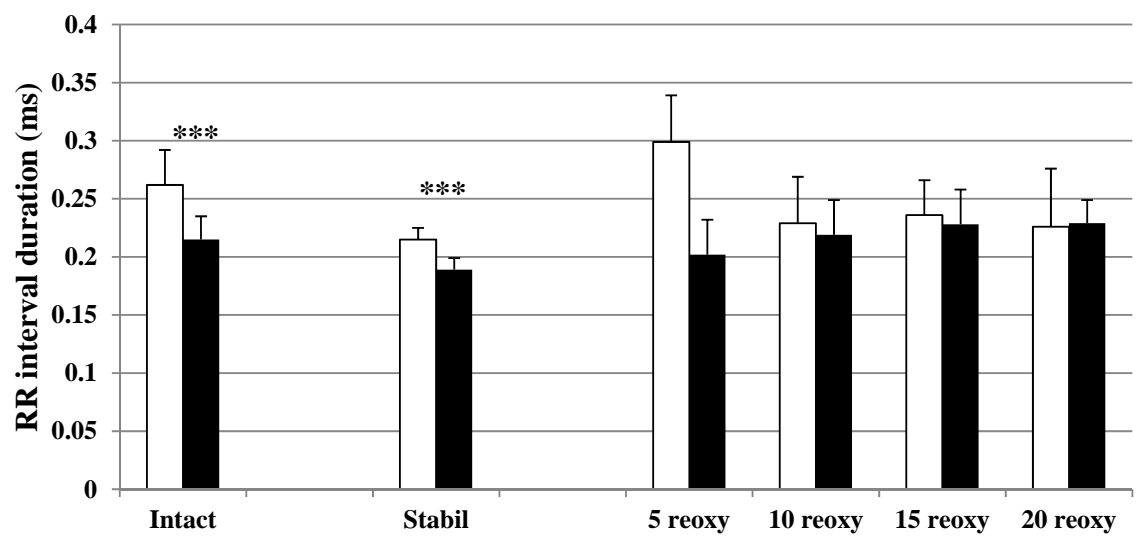

Figure 5. Mean \pm SD values of the RR interval duration in intact animals (Intact), after tracheotomy, thoracotomy and 5 min. stabilization (Stabil) and after 20 minute of artificial reoxygenation. Empty and black columns refer to light and dark parts of the day, respectively. The level of significance of differences between the light and dark part of the rat regime day is indicated by the symbol $\left.{ }^{* * *} p<0,001\right)$.

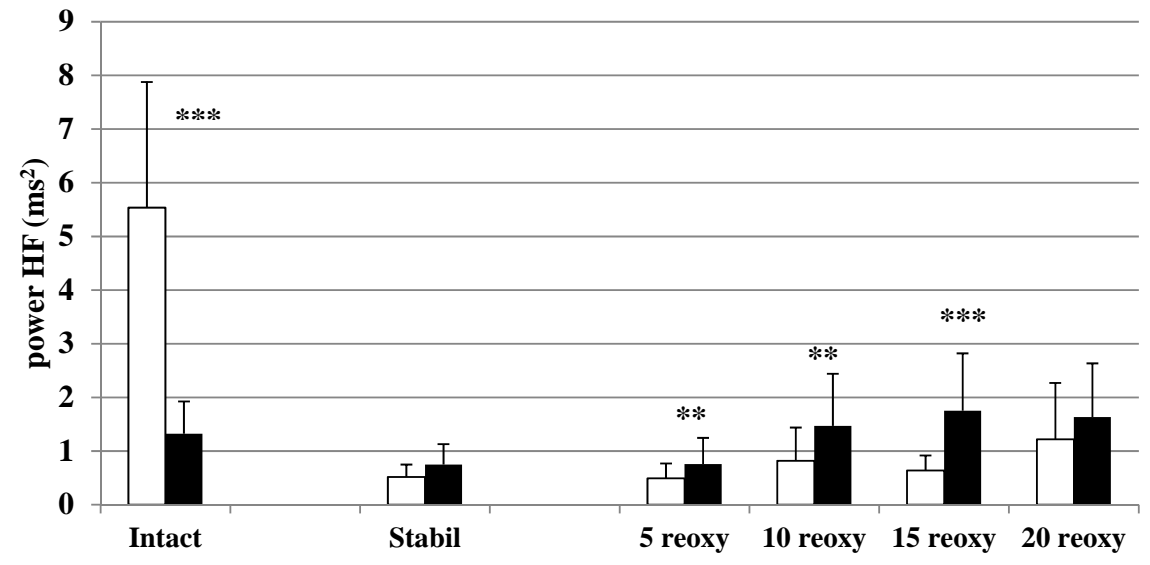

Figure 6. Mean \pm SD values of the power HF in intact animals (Intact), after tracheotomy, thoracotomy and 5 min. stabilization (Stabil) and after 20 minute of artificial reoxygenation. Empty and black columns refer to light and dark parts of the day, respectively. The level of significance of differences between the light and dark part of the rat regime day is indicated by the symbol (** $\left.p<0,01,{ }^{* * *} p<0,001\right)$. 


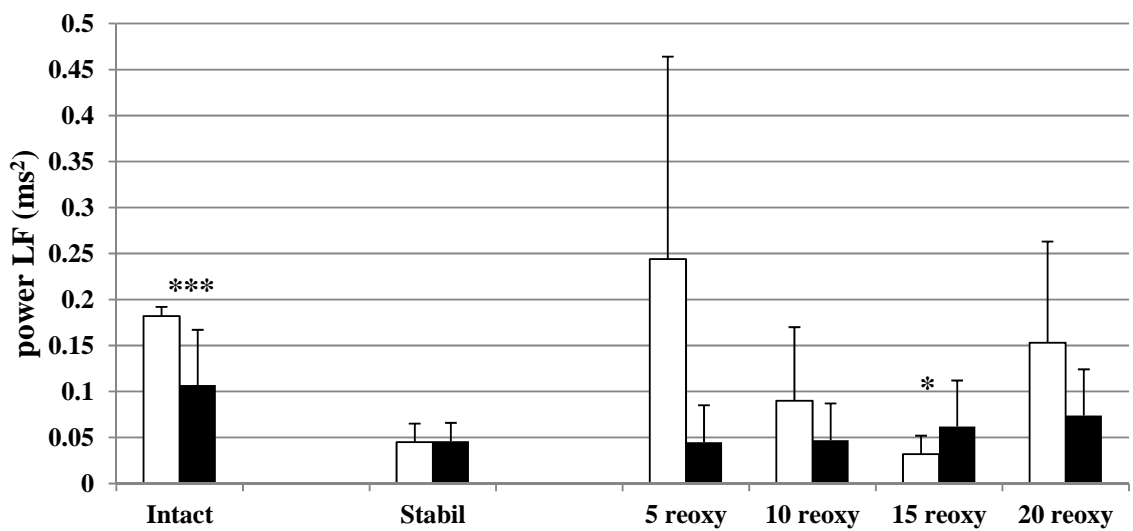

Figure 7. Mean \pm SD values of the power LF in intact animals (Intact), after tracheotomy, thoracotomy and 5 min. stabilization (Stabil) and after 20 minute of artificial reoxygenation. Empty and black columns refer to light and dark parts of the day, respectively. The level of significance of differences between the light and dark part of the rat regime day is indicated by the symbol (* $\left.p<0,05,{ }^{* * *} p<0,001\right)$.

LF and VLF components of the HRV did not show any regular and predictable changes in the duration of the experiment. Although significant LD differences was found in intact animals with longer duration in the light part, changes in these component practically did not depend on the LD cycle during the recovery of pulmonary ventilation (figure 7 and 8).

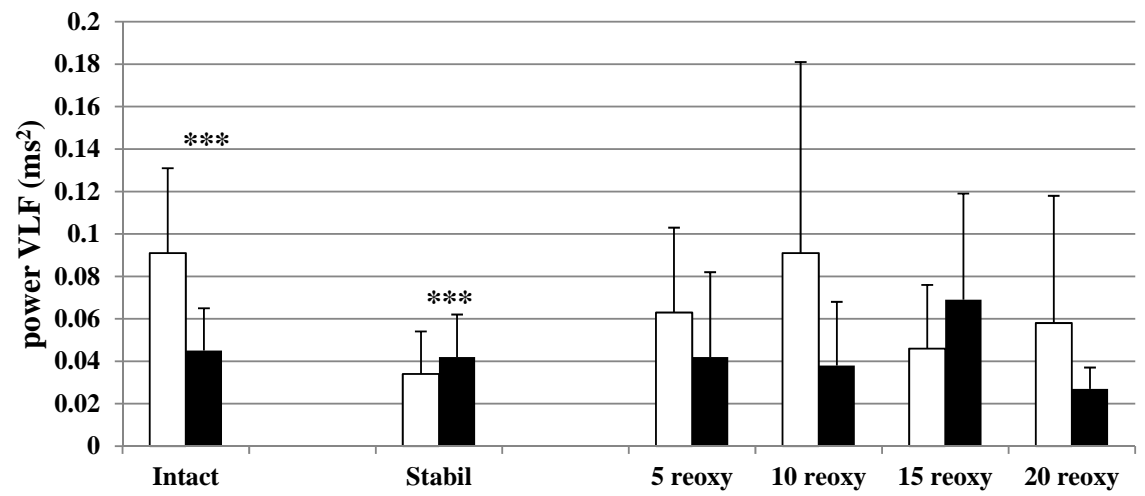

Figure 8. Mean \pm SD values of the power VLF in intact animals (Intact), after tracheotomy, thoracotomy and 5 min. stabilization (Stabil) and after 20 minute of artificial reoxygenation. Empty and black columns refer to light and dark parts of the day, respectively. The level of significance of differences between the light and dark part of the rat regime day is indicated by the symbol (*** $p<0,001)$.

Ketamine/xylazine anaesthesia significantly increases the parasympathetic activity and decreases sympathetic and baroreceptor activity independently of the cycle of light and dark alternation. Under ketamine/xylazine anaesthesia, the RR interval duration preserves the 
significant LD differences resulting of the parasympathetic and baroreceptor activities as well in a dark (active) as well as in the light (inactive) mode on the rat day. Share of RR intervals is negligible to the sympathetic activity.

Reoxygenation the following immediately after the apnoic episode does not alter the relative abundance of the individual divissions of the ANS, but it is preserved the dominant parasympathetic activity (figure 9 and 10). During the light part of the day, the activity of the parasympathetic fluctuates randomly, but in a dark part of the day, we can see an increasing trend with time the duration of the reoxygenation. This tendency is comparable to the changes in the heart's electrical stability, which increases with the duration of the reoxygenation. Baroreceptor activity in the light part of the day fluctuates randomly, but in a dark part of the growing trend, which is probably associated with the predominant activity of the parasympathetic. Sympathetic activity during the reoxygenation shows no predictable changes in either of the lighted parts of the day.

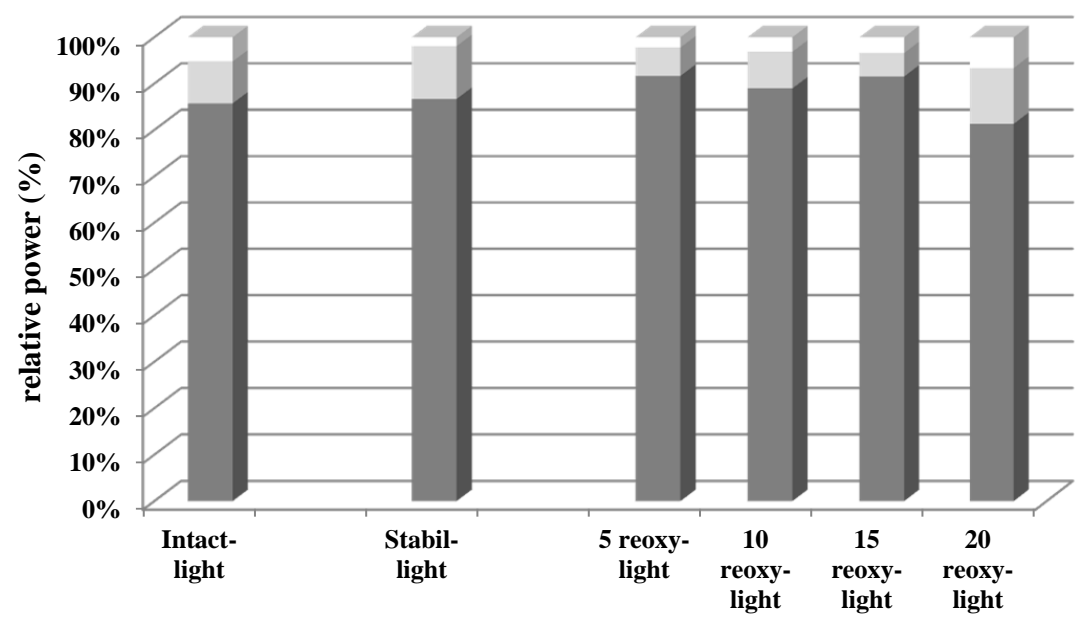

Figure 9. Relative power of the single components of HRV during the light part of the rat regime day. Black shadow power HF, middle shadow - power LF and light shadow - power VLF.

In intact animals, correlation coefficients revealed that durations of RR intervals is influenced by parasympathetic and baroreceptor activities in both lighted parts of the day. Reoxygenation eliminated this dependence (table 1). We concluded that proarrythmogenic or antiarrhythmogenic effect of reoxygenation is probably connected with the changes in the parasympathetic activity and is dependent on the rat active or passive period in a ketamine/xylazine anaesthesia.

In ketamine/xylazine-anaesthetized rats, significant LD differences were preserved, in contrast to pentobarbital-anaesthetized rats (Svorc Jr. et al., 2013). Although the disruptive effect of ketamine on circadian rhythms has been described by others (Prudian et al., 1997; Pelissier et al., 1998), this effect was associated with modification of acrophase, amplitude or mesor, but 
without loss of daily rhythmicity. Ketamine/xylazine anaesthesia reduces heart rate in isolated rat heart preparations (Aronson and Hanno, 1978) and also in in vivo conditions (Salerno and vanTienhoven, 1976; Sapru and Krieger, 1979; Brown et al., 1994; Hoque et al., 1996; Maignan et al., 2000). It prolongs RR and QT intervals (Aronson and Hanno, 1978), decreases blood pressure (Sapru and Krieger, 1979), renal sympathetic activity and attenuates baroreflex sensitivity in vivo (Akine et al., 2001). On the other hand, Reid et al. (2003), described a stimulating effect on cardiac function during resuscitation. Unfortunately, in the abovementioned studies, the clock time of the experiment was not reported, nor was the synchronization of animals to an LD regimen described.

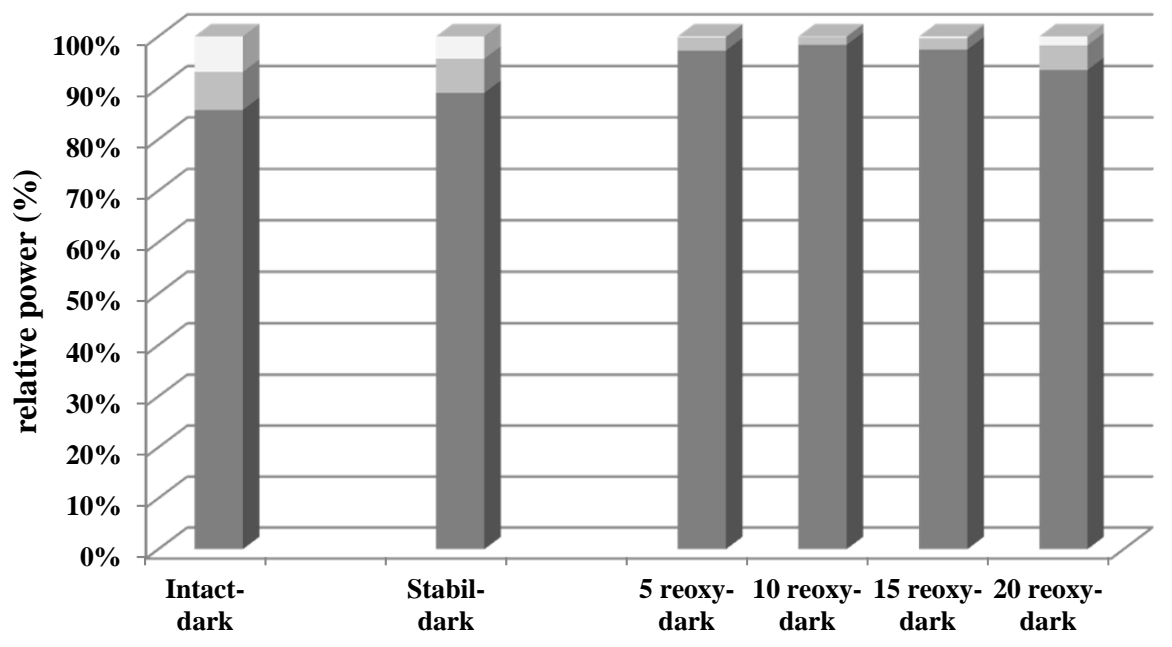

Figure 10. Relative power of the single components of HRV during the dark part of the rat regime day. Black shadow - power HF, middle shadow - power LF and light shadow - power VLF.

\begin{tabular}{c|cc|cc|cc}
\hline \multicolumn{2}{c}{ light } & dark & light & dark & light & dark \\
\hline HF-RR & $r=0,48$ & $r=0,44$ & $r=0,43$ & $r=0,37$ & $r=0,05$ & $r=0,5$ \\
\hline LF-RR & $r=0,46$ & $r=0,45$ & $r=0,57$ & $r=0,56$ & $r=-0,1$ & $r=0,1$ \\
\hline VLF-RR & $r=0,19$ & $r=0,14$ & $r=0,53$ & $r=0,19$ & $r=-0,27$ & $r=-0,02$ \\
\hline
\end{tabular}

Table 1. Correlation coefficients between RR intervals duration and single parameters of HRV in the single experimental steps.

Results demostrate that ketamine/xylazine anaesthesia preferably increases parasympathetic activity and suppresses sympathetic and baroreceptor activity, resulting in marked bradycardia independently of the LD cycle. Presence of LD differences refers to the fact that this type 
of anaesthesia may be applicable in chronobiological studies. However, it may be problematic for cardiovascular research owing to serious bradycardia.

\section{Conclusions}

We concluded that the electrical myocardial properties are influenced by the changing cycles of light and darkness also in ketamine/xylazine anaesthesia.

- heart rate and electrical stability of the heart are significantly reduced by apneic episode regardless of the lighted period (proarrhythmogenic effect). Electrocardiographic parameters (PQ and QT interval) prolong with the duration of apneic episode regardless of the LD cycle. Possible cause of ventricular arrhythmias (ventricular arrhythmias originating from disorders of the impulse production and conduction or ventricular arrhythmias originating from an enlarged dispersion of refractory periods) probably depends not only on the duration of apneic episode, but also on the LD cycle. Short-term asphyxia increases vulnerability to the arrhythmias originating from disorders of the impulse production and conduction but does not disturb LD dependence. Long-term apneic episode, connected with more serious asphyxia continue increases vulnerability to this type of arrhythmias but independently on the LD cycle. The opposite situation is true of the QT interval.

- recovery of the pulmonary ventilation after apneic episodes can also contribute to heart rhythm disorders, but this is dependent upon the light (non-active)-dark (active) cycle. In the dark part of the day, the gradual decrease of the myocardial vulnerability is associated with the duration of reoxygenation (anti-arrhythmogenic effect) compared with the light part of the day, where the contrary tendency was observed (pro-arrhythmogenic effect). Reoxygenation disturbs LD differences in the heart rate as well as in QT interval duration, but recovers PQ interval duration to the pre-asphyxic values with preservation of the LD differences observed in intact animals.

- ketamine/xylazine anaesthesia increases parasympathetic activity, inhibits baroreceptor and sympathetic activity in the same way in both lighted periods. Dominant influence of parasympathetic autonomic nervous system was preserved during experiment. In these conditions, the heart is controled by the parasympathetic divission without the influence of the sympathetic autonomic nervous system.

\section{Author details}

Pavol Svorc ${ }^{1,2}$, Ivana Bacova ${ }^{1}$, Pavol Svorc, Jr. ${ }^{2}$, Monika Novakova ${ }^{1}$ and Alexander Marossy ${ }^{1}$

1 Department of Physiology, Medical Faculty, Safarik University, Kosice, Slovak Republic

2 Department of Physiology, Medical Faculty, Ostrava University, Ostrava, Czech Republic 


\section{References}

[1] Akerstedt, T. \& Wright, K.P., Jr. (2009). Sleep loss and fatigue in shift work and shift work disorder. Sleep Medicine Clinics, Vol. 4, No. 2, (June 2009), pp. 257-271, ISSN: $1556407 X$.

[2] Akine, A.; Suzuka, H.; Hayashida, Y. \& Kato, Y. (2001). Effects of ketamine and propofol on autonomic cardiovascular function in chronically instrumented rats. Autonomic Neuroscience-Basic \& Clinical, Vol. 87, No 2-3, (Mar 23 2001), pp. 201-208, ISSN: 1566-0702.

[3] Alva, N.; Palomeque, J. \& Carbonell, T. (2006). Nitric oxide induced by ketamine/ xylazine anesthesia maintains hepatic blood flow during hypothermia. Nitric Oxide Biology and Chemistry, Vol. 15, No. 1, (Aug 2006), pp. 64-69, ISSN: 1089-8603

[4] Amitzur, G.; Schoels, W.; Visokovsky, A.; Lev-ran, V.; Novikov, I.; Mueller, M.; Kraft, P.; Kaplinsky, E. \& Eldar, M. (2000). Role of sodium channels in ventricular fibrillation: A study in nonischemic isolated hearts. Journal of Cardiovascular Pharmacology, Vol. 36, No. 6, (Dec 2000), pp. 785-793, ISSN: 0160-2446.

[5] Arias, M.A. \& Sanches, A.M. (2007). Obstructive sleep apnea and its relationship to cardiac arrhythmias. Journal of Cardiovascular Electrophysiology, Vol. 18, No. 9, (Sep 2007), pp. 1006-1014, ISSN: 1045-3873.

[6] Aronow, W.S. (2007). Cardiovascular manifestations seen in obstructive sleep apnea. Comparative Therapy, Vol. 33, No. 2, pp. 82-86, ISSN: 1559-1190

[7] Aronson, C.E. \& Hanno, E.R.S. (1978). Effects of ketamine on the isolated perfused rat heart. General Pharmacology, Vol. 9, No. 4, (1978), pp. 249-255, ISSN: 0306-3623.

[8] Auger, R.R. \& Morgenthaler, T.I. (2009). Jet lag and other sleep disorders relevant to the travel. Travel Medicine and Infectious Diseases, Vol.7, No. 2, (Mar 2009), pp. 60-68, ISSN: $1477-8939$.

[9] Aydin, M.; Altin, R.; Ozeren, A.; Kart, L.; Bilge, M. \& Unalacak, M. (2004). Cardiac autonomic activity in obstructive sleep apnea - Time-dependent and spectral analysis of heart rate variability using 24-hour holter electrocardiograms. Texas Heart Institute Journal, Vol. 31, No. 2, (2004), pp. 132-136, ISSN: 0730-2347.

[10] Aytemir, K.; Deniz, A.; Yavuz, B.; Demir, A.U.; Sahiner, L.; Ciftci, O.; Tokgozoglu, L.; Can, I.; Sahin, A. \& Oto, A. (2007). Increased myocardial vulnerability and autonomic nervous system imbalance in obstructive sleep apnea syndrome. Respiratory Medicine, Vol. 101, No. 6, (Jun 2007), pp. 1277-1282, ISSN: 0954-6111.

[11] Bayram, N.A. \& Diker, E. (2008). Obstructive sleep apnea syndrome and cardiac arrhythmias. Turk Kardiyol Dern Ars, Vol. 36, No. 1, pp. 44-50. PMID: 18453787 [PubMed - indexed for MEDLINE]. 
[12] Bacova, I.; Svorc, Jr. P.; Kundrik, M. \& Fulton, B.L. (2010). Light-dark dependence of electrocardiographic changes during asphyxia and reoxygenation in a rat model. Central European Journal of Medicine, Vol. 5, No. 5, (Oct 2010), pp. 611-619, ISSN: 1895-1058.

[13] Billman, G.E.; Avendano, C.E.; Halliwill, J.R. \& Burroughs, J.M. (1993). The effects of the ATP-dependent potassium channel antagonist, glyburide, on coronary bloodflow and susceptibility to ventricular fibrillation in unanesthetized dogs. Journal of Cardiovascular Pharmacology, Vol. 21, No. 2, (Feb 1993), pp. 197-204, ISSN: 0160-2446.

[14] Bishop, B.; Silva, G.; Krasney, J.; Nakano, H.; Roberts, A.; Farkas, G.; Rifkin, D. \& Shucard, D. (2001). Ambient temperature modulates hypoxic - induced changes in rat body temperature and activity differentially. American Journal of Physiology, Vol. 280, No. 4, (Apr 2001), pp. R1190-R1196, ISSN: 0363-6119.

[15] Bosco, G.; Ionadi, A.; Panico, S.; Faralli, F.; Gagliardi, R.; Data, P. \& Mortola, J.P. (2003). Effects of hypoxia on the circadian patterns in men. High Altitude Medicine and Biology, Vol. 4, No. 3, (Feb 2003), pp. 305-318, ISSN: 1527-0297.

[16] Bounhoure, J.P.; Galinier, M.; Didier, A. \& Leophonte, P. (2005). Sleep apnea syndromes and cardiovascular disease. Bulletin de l Academie Nationale de Medecine, Vol. 189, No. 3, (Mar 2005), pp. 445-459, ISSN: 0001-4079.

[17] Brown, D.R.; Brown, L.V.; Patwardhan, A. \& Randall, D.C. (1994). Sympathetic activity and blood-pressure are tightly coupled at $0,4 \mathrm{~Hz}$ in conscious rats. American Journal of Physiology-Regulatory Integrative and Comparative Physiology, Vol. 267, No. 5, (Nov 1994), pp. 1378-1384, ISSN: 0363-6119.

[18] Budhiraja, R. \& Quan, S.F. (2005). Sleep-disordered breathing and cardiovascular health. Current Opinion in Pulmonary Medicine, Vol. 11, No. 6, (Nov 2005), pp. 501-506, ISSN: 1070-5287.

[19] Bugge, E.; Gamst, T.M.; Hegstad, A.C.; Andreassen, T. \& Ytherus, K. (1997). Mepacrine protects the isolated rat heart during hypoxia and reoxagenation - but not by inhibition of phospholipase A2. Basic Research in Cardiology, Vol. 92, No. 1, (Feb 1997), pp. 17-24, ISSN: 0300-8428.

[20] Buggress, K.R. (1998). Central sleep apnoe and heart failure. Respirology, Vol. 3, No. 1, (Mar 1998), pp. 1-11. ISSN: 1440-1843, DOI: 10.1046/j.1440-1843.1998.d01-10.x

[21] Carmeliet, E. (1986). The slow inward current: non-voltage-clamp studies. In: The slow invard current and cardiac arrhythmias, Zipes, D.P.; Bailey, J.C.; Elharrar, V, pp. 97-110, Elsevier Science Publishers BV, ISBN: 978-94-009-8890-3, Hague/Boston/ London.

[22] Chen, C.C.; Chen, S.A.; Tai, C.T.; Kuo, T.B.J.; Chang, M.S. \& Prystowsky, E.N. (2001). Hyperventilation facilitates induction of supraventricular tachycardia: A novel meth- 
od and the possible mechanism. Journal of Cardiovascular Electrophysiology, Vol. 12, No. 11, (Nov 2001), pp. 1242-1246, ISSN: 1045-3873.

[23] Chowdhuri, S.; Crook, E.D.; Taylor, H.A. Jr. \& Badr, M.S. (2007). Cardiovascular complications of respiratory diseases. American Journal of the Medical Sciences, Vol. 334, No. 5, (Nov 2007), pp. 361-380, ISSN: 0002-9629.

[24] Cope, D.K.; Impastato, W.K.; Cohen, M.V. \& Downey, J.M. (1997). Volatile anesthetics protect the ischemic rabbit myocardium from infarction. Anesthesiology, Vol. 86, No. 3, (Mar 1997), pp. 699-709, ISSN: 0003-3022.

[25] Cutler, M.J.; Hamdam, A.L.; Hamdam, M.H.; Ramaswamy, K. \& Smith, M.L. (2002). Sleep apnea: from the nose to the heart. Jornal of the American Board of Family Medicine, Vol. 15, No. 2, (Mar 2002), pp. 128-141, ISSN: 1558-7118.

[26] Daccarett, M.; Segerson, N.M.; Hamdan, A.L.; Hill, B. \& Hamdan M.H. (2008). Relation of daytime bradyarrhythmias with high risk features of sleep apnea. American Journal of Cardiology, Vol. 101, No. 8, (Apr 15 2008), pp. 1147-1150, ISSN: 0002-9149.

[27] Daut, J.; Maierrudolph, W.; vonBeckerath, N.; Mehrke, G.; Gunther, K. \& GoedelMeinen, L. (1990). Hypoxic dilation of coronary-arteries is mediated by ATP-sensitive potassium channels. Science, Vol. 247,No. 4948, (Mar 16 1990), pp. 1341-1344, ISSN: 0036-8075.

[28] Dunai, A.; Musci, I.; Juhasz, J. \& Novak, M. (2006). Obstructive sleep apnea and cardiovascular disease. Orvosi Hetilap, Vol. 147, No. 48, (2006-Dec-3), pp. 2303-2311, ISSN: 0030-6002.

[29] Farver, T.B.; Haskins, S.C. \& Patz, J.D. (1986). Cardiopulmonary effects of acepromazine and of the subsequent administration of ketamine in the dog. American Journal of Veterinary Research, Vol. 47, No. 3, (Mar 1986), pp. 631-635, ISSN: 0002-9645.

[30] Foster, G.T.; Vaziri, N.D. \& Sassoon, C.S. (2001). Respiratory alkalosis. Respiratory Care, Vol. 46, No. 4, (2001-Apr), pp. 384-391, ISSN: 0020-1324.

[31] Froldi, G.; Pandolfo, L.; Chinellato, A.; Ragazzi, E.; Caparrotta, L. \& Fassina, G. (1994). Protection of atrial function in hypoxia by high potassium concentration. General Pharmacology, Vol. 25, No. 3, (May 1994), pp. 401-407, ISSN: 0306-3623.

[32] Gami, A.S.; Howard, D.E.; Olson, E.J. \& Somers, V.K. (2005). Day-night pattern of sudden death in obstructive sleep apnea. New England Journal of Medicine, Vol. 352, No. 12, (Mar 2005), pp. 1206-1214, ISSN: 0028-4793.

[33] Gilpin, E.A.; Hjalmarson, A. \&, Ross, J. (1990). Subgroups of patients with atypical circadian patterns of symptom oset in acute myocardial infardction. American Journal of Cardiology, Vol. 66, No. 16, (Nov 6 1990), pp. 7G-11G, ISSN: 0002-9149.

[34] Gresova, S.; Tomori, Z.; Kurpas, M.; Marossy, A.; Vrbenska, A.; Kundrik, M. \& Donic, V. (2009). Blood pressure increase detected by ambulatory monitoring correlates 
with hypoxemia reflecting sleep apnea severity. Central European Journal of Medicine, Vol. 4, No. 2, (Jun 2009), pp. 222-232, ISSN: 1895-1058.

[35] Griffiths, E,J.; Ocampo, C.J.; Savage, J.S.; Stern, M.D. \& Silverman, H.S. (2000). Protective effects of low and high doses of cyclosporin A against reoxygenation injury in isolated rat cardiomyocytes are associated with differrential effects on mitochondrial calcium levels. Cell Calcium, Vol. 27, No. 2, (Feb 2000), pp. 87-95, ISSN: 0143-4160.

[36] Gunez, Y.; Tuncer, M.; Guntekin, U.; Akdag, S. \& Gumrukcuoglu, H.A. (2008). Lack of diurnal variation of P-wave and QT dispersions in patients with heart failure. PACE - Pacing and Clinical Electrophysiology, Vol. 31, No. 8, (Aug 2008), pp. 974-978, ISSN: 0147-8389.

[37] Hayashida, Y.; Hirakawa, H.; Nakamura, T. \& Maeda, M. (1996). Chemoreceptors in autonomic responses to hypoxia in conscious rats. In: Frontiers in Arterial Chemoreception, Zapata, P.; Eyzaguirre, C. \& Torrance, R.W., pp. 439-442, Plenum Press, ISBN: 0-306-45490-4, New York.

[38] Henry, R.; Casto, R. \& Printz, M.P. (1990) Diurnal cardiovascular patterns in spontaneously hypertensive and Wistar-Kyoto rats. Hypertension, Vol. 16, No. 4, (Oct 1990), pp. 422-428, ISSN: 0194-911X.

[39] Hinojosa-Laborde, C. \& Mifflin, S.W. (2005). Sex differences in blood pressure response to intermittent hypoxia in rats. Hypertension, Vol. 46, No. 4, (Oct 2005), pp. 1016-1021, ISSN: 0194-911X.

[40] Hsu, W.H.; Bellin, S.I.; Dellmann, H.D.; Habil, V. \& Hanson, C.E. (1986). Xylazineketamine - induced anesthesia in rats and its antagonism by yohimbine. Journal of the American Veterinary Association, Vol. 189, No. 9, (Nov 1 1986), pp. 1040-1043, ISSN: 0003-1488.

[41] Hoque, A.M.; Marczin, N.; Catravas, J.D. \& Fuchs, L.C. (1996). Anesthesia with sodium pentobarbital enhances lipopolysaccharide-induced cardiovascular dysfunction in rats. Shock, Vol. 6, No. 5, (Nov 1996), pp. 365- 370, ISSN: 1073-2322.

[42] Kaplan, J.L.; Gao, E.; deGaravilla, L.; Victain, M.; Minczak, B. \& Dalsey, W.C. (2003). Adenosine A1 antagonism attenuates atropine-resistant hypoxic bradycardia in rats. Academic Emergency Medicine, Vol. 10, No. 9, (Sep 2003), pp. 923-930, ISSN: 1069-6563.

[43] Kuniyoshi, F.H.S.; Garcia-Touchard, A.; Gami, A.S.; Romero-Corral, A.; van der Walt, C.; Pusalavidyasagar, S.; Kara, T.; Caples, S.M.; Pressman, G.S.; Vasquez, E.C.; Lopez-Jimenez, F. \& Somers, V.K. (2008). Day-night variation of acute myocardial infarction in obstructive sleep apnea. Journal of the American College Cardiolology, Vol. 52, No. 5, (Jul 2008), pp. 343-346, ISSN: 0735-1097.

[44] Leone, R. Jr. \& Merrill, G.F. (1995). Inhibition of adenosine deaminase and administration of adenosine increase hypoxia induced ventricular ectopy. Basic Research in Cardiology, Vol. 90, No. 3, (May-Jun 1995), pp. 234-239, ISSN: 0300-8428. 
[45] Lubbe, W.F.; Bricknell, O.L. \& Marzagao, C. (1975). Ventricular fibrillation threshold and vulnerable period in the isolated perfused rat heart. Cardiovascular Research, Vol. 9, No. 5, (Sep 1975), pp. 613-620, ISSN: 0008-6363.

[46] Maignan, E.; Dong, W.X.; Legrand, M.; Safar, M. \& Cuche, J.L. (2000). Sympathetic activity in the rat: effects of anaesthesia on noradrenaline kinetics. Journal of the Autonomic Nervous System, Vol. 80, No. 1-2, (Apr 12 2000), pp. 46-51, ISSN: 0165-1838.

[47] Morita, Y.; Murakami, T.; Iwase, T.; Nagal, K.; Nawada, R.; Kouchi, I.; Akao, M. \& Sasayama, S. (1997). $\mathrm{K}_{\text {ATP }}$ channels contribute to the cardioprotection of preconditioning independent of anaesthetics in rabbit hearts. Journal of Molecular and Cellular Cardiology, Vol. 29, No. 4, (Apr 1997), pp. 1267-1276, ISSN: 0022-2828.

[48] Mortola, J.P. \& Seifert, E.L. (2000). Hypoxic depression of circadian rhythms in adult rats. Journal of Applied Physiology. Vol. 88, No. 2, (Feb 2000), pp. 365-368, ISSN: 8750-7587.

[49] Mortola, J.P. (2007). Hypoxia and circadian patterns. Respiratory Physiology E Neurobiology, Vol. 158, No. 2-3, (Sep 30 2007), pp. 274-279, ISSN: 1569-9048.

[50] Mubagwa, K.; Kaplan, P. \& Flameng, W. (1997). The effects of ryanodine on calcium uptake by the sarcoplasmic reticulum of ischemic and reperfused rat myocardium. Fundamental and Clinical Pharmacology, Vol. 11, No. 4, (1997), pp. 315-321, ISSN: 0767-3981.

[51] Mukai, M.; Terada, H.; Sugiyama, S.; Satoh, H. \& Hayashi, H. (2000). Effects of a selective inhibitor of $\mathrm{Na}^{+} / \mathrm{Ca}^{2+}$ exchange, KB-R7943, on reoxygenation - induced injuries in guinea pig papillary muscles. Journal of Cardiovascular Pharmacology, 2000, Vol. 36, No. 3, (Sep 2000), pp. 416-416, ISSN: 0160-2446.

[52] Nishimura, M.; Tanaka, H.; Homma, N.; Matsuzawa, T. \& Watanabe, Y. (1989). Ionic mechanisms of the depression of automaticity and conduction in the rabbit atrioventricular node caused by hypoxia or metabolic inhibition and protective action of glucose and valine. American Journal of Cardiology, Vol. 64, No. 20, (Dec 1989), pp. J24J28, ISSN: 0002-9149.

[53] Noda, A.; Yasuma, F.; Okada, T.; Yokota, M. (1988). Circadian rhythm of autonomic activity in patients with obstructive sleep apnea syndrome. Clinical Cardiology, Vol. 21, No. 4, (Apr 1998), pp. 271-276, ISSN: 0160-9289.

[54] Noma, A. \& Shibasaki, T. (1985). Membrane current through adenosine-triphosphate-regulated potassium channels in guinea-pig ventricular cells. Journal of Physiology-London, Vol. 363, No. Jun, (1985), pp. 463-480, ISSN: 0022-3751.

[55] Opie, L.H.; Nathar, D. \& Lubbe, W.F. (1979). Biochemical aspects of arrhythmogenesis and ventricular fibrillation. American Journal of Cardiology, Vol. 43, No. 1, (Jan 1979), pp. 131-148, ISSN: 0002-9149.

[56] Overgaard, J.; Gesser, H.; Wang, T.; Tribute, T.O. \& Lutz, P.L. (2007). Cardiac performance and cardiovascular regulation during anoxia/hypoxia in freshwater turtles. 
Journal of Experimental Biology, Vol. 210, (May 2007), pp. 1687-1699, ISSN: 1477-9145, doi:10.1242/jeb.001925.

[57] Parish, J.M. \& Somers, V.K. (2004). Obstructive sleep apnea and cardiovascular disease. Mayo Clinic Proceedings, Vol. 79, No. 8, (Aug 2004), pp. 1036-1046, ISSN: 0025-6196.

[58] Park, D.H.; Shin, C.J.; Hong, S.C.; Yu, J.; Ryu, S.H.; Kim, E.J.; Shin, H.B. \& Shin, B.H. (2008). Correlation between the severity of obstructive sleep apnea and heart rate variability indices. Journal of Korean Medical Science, Vol. 23, No. 2, (Apr 2008), pp. 226-231, ISSN: 1011-8934.

[59] Patel, N. \& Rosen, I. (2007). Sleep apnea and cardiovascular disease: Association, causation, and implication. Clinical Pulmonary Medicine, Vol. 14, No. 4, (July 2007), pp. 225-231. doi: 10.1097/CPM.0b013e3180cac6d8

[60] Pelissier, A.L.; Gantenbein, M.; Prudian, F. \& Bruguerolle, B. (1998). Influence of general anaethetics on circadian rhythms of heart rate, body temperature and locomotor activity in rats. Sciences et Techniques de l Animal de Laboratoire, Vol. 23, No. 2, (1998), pp. 91-98, ISSN: 0339-722X.

[61] Perchenet, L. \& Kreher, P. (1995). Mechanical and electrophysiological effects of preconditioning in isolated ischemic/reperfused rat heart. Journal of Cardiovascular Pharmacology, Vol. 26, No. 5, (Nov 1995), pp. 831-840, ISSN: 0160-2446.

[62] Portaluppi, F. \& Hermida, R.C. (2007). Circadian rhythms in cardiac arrhythmias and opportunities for their chronotherapy. Advanced Drug Delivery Reviews, Vol. 59, No. 9-10, (Aug 31 2007), pp. 940-951, ISSN: 0169-409X.

[63] Prudian, F.; Gantenbein, M.; Pelissier A.L.; Attolini, L. \& Bruguerolle, B. (1997). Daily rhythms of heart rate, temperature and locomotor activity are modified by anaesthetics in rats: A telemetric study. Naunyn-Schmiedebergs Archives Pharmacology, Vol. 355, No. 6, (Jun 1997), pp. 774-778, ISSN: 0028-1298.

[64] Reid, K.H.; Paskitti, M.; Guo, S.Z.; Schmeizer, T. \& Iyer, V. (2003). Experience with ketamine and sodium pentobarbital as anesthetics in a rat model of cardiac arrest and resuscitation. Resuscitation, Vol. 57, No. 2, (May 2003), pp. 201-210, ISSN: 0300-9572.

[65] Richardson, G.S. (2005). The human circadian system in normal and disordered sleep. Journal of Clinical Psychiatry, Vol. 66, suppl 9, (2005), pp. 7-9, ISSN: 0160-6689.

[66] Roche, F.; Xuong, A.N.T.; Court-Fortune, I.; Costes, F.D.; Pichot, V.; Duverney, D.; Vergnon, J.M.; Gaspoz, J.M. \& Barthelemy, J.C. (2003). Relationship among the severity of sleep apnea syndrome, cardiac arrhythmias, and autonomic imbalance. PACE-Pacing and Clinical Electrophysiology, Vol. 26, No. 3, (Mar 2003), pp. 669-677, ISSN: 0147-8389. 
[67] Salerno, A. \& van Tienhoven, A. (1976). The effect of ketamine on heart rate, respiration rate and EEG of white leghorn hens. Comparative Biochemistry and Physiology. C: Comparative Pharmacology, Vol. 55, No. 1, (1976), pp. 69-75, ISSN: 0306-4492.

[68] Sanguinetti, M.C.; Scott, A.L.; Zingaro, G.J. \& Siegl. P.K.S. (1988). BRL-34915 (Cromakalim) activates ATP-sensitive $\mathrm{K}^{+}$current in cardiac-muscle. Proceedings of the National Academy of Sciences of the United States of America, Vol. 85, No. 21, (Nov 1988), pp. 8360-8364, ISSN: 0027-8424.

[69] Sapru, H.N. \& Krieger, A.J. (1979). Cardiovascular and respiratory effects of some anesthetics in the decerebrate rat. European Journal of Pharmacology, Vol. 53, No. 2, (1979Jan-1), pp. 151-158, ISSN: 0014-2999.

[70] Sawanobori, T.; Adaniya, H.; Yukisada, H. \& Hiraoka, M. (1995). Role for ATP - sensitive $\mathrm{K}^{+}$channel in the development of $\mathrm{A}-\mathrm{V}$ block during hypoxia. Journal of Molecular and Cellular Cardiology, Vol. 27, No. 1, (Jan 1995), pp. 647-657, ISSN: 0022-2828.

[71] Schulz, R.; Grebe, M.; Eisele, H.J.; Mayer, K.; Weissmann, N. \& Seeger, W. (2006). Obstructive sleep apnea-related cardiovascular disease. Medizinische Klinik, Vol. 101, No. 4, (Apr 15 2006), pp. 321-327, ISSN: 0723-5003.

[72] Shinmura, K.; Tani, M.; Suganuma, Y.; Hasegawa, H.; Ebihara, Y.; Nakamura, Y. \& Asakura, Y. (1997). Effects of alpha(1)-adrenoreceptor subtype blockade on ischemia - reperfusion injury. Japanese Circulation Journal, Vol. 61, No. 11, (Nov 1997), pp. 927935, ISSN: 0047-1828.

[73] Sumitra, M.; Manikandan, P.; Rao, K.V.K.; Nayeem, M.; Manohar, B.M. \& Puvanakrishnan, R. (2004). Cardiorespiratory effects of diazepam-ketamine, xylazine-ketamine and thiopentone anesthesia in male Wistar rats - A comparative analysis. Life Science, Vol. 75, No.15, (Aug 27 2004), pp. 1887-1896, ISSN: 0024-3205.

[74] Svorc, P.; Wilk, P.; Murár, J. Podlubny I.; Kujanik S.; Bracokova I. \& Murin M. (1994). Circadian rhythm of the ventricular fibrillation threshold in female Wistar rats. Physiological Research, Vol. 43, No. 6, (Sep 1994), pp. 355-358, ISSN: 0369-9463.

[75] Svorc, P.; Podlubny, I.; Kujanik, S. \& Bracokova, I. (1997). 24h rhythm of the vetricular fibrillation threshold during normal and hypoventilation in female Wistar rats. Chronobiology International, Vol. 14, No. 4, (Feb 1997), pp. 363-370, ISSN: 0742-0528.

[76] Svorc, P.; Bracokova, I. \& Podlubny, I. (2000). Relation of ventricular fibrillation threshold to heart rate during normal ventilation and hypoventilation in female Wistar rats: A chronophysiological study. Physiological Research, Vol. 49, No. 6, (Mar 2000), pp. $711-719$, ISSN 0862-8408.

[77] Svorc, P.; Bracokova, I.; Bacova, I. \& Svorcova, E. (2009). Acid-base balance and artifitial controlled ventilation in Wistar rats, Chronobiological view. Abstract book from The third International Congress of Applied Chronobiology and Chronomedicine, Akko Israel, pp. 67. 
[78] Svorc, P. Jr.; Svorc, P. \& Fulton, B.L. (2011). Chronobiological aspects of reoxygenation impact on the heart rhythm disorders in Wistar rat model. Trends in Comp Biochem Physiol, Vol. 15, pp. 55-61, ISSN: 0972-4540.

[79] Svorc, P.; Marossy, A.; Svorc, P. Jr; Gresova, S.; Buzga, M. \& Fulton, B.J. (2012). Chronobiological aspects of the heart rhythm disorders at the change of pulmonary ventilation in rat model. In: Cardiac arrhythmias. New Considerations, Breijo-Marquez, F.R, pp. 193-226, InTech, ISBN: 978-953-51-0126-0, Rijeka, Croatia

[80] Svorc, P. Jr.; Bacova, I.; Svorc, P. \& Buzga, M. (2013). Autonomic nervous system under ketamine/xylazine and pentobarbital anaesthesia in a Wistar rat model: Chronobiological view. Prague Medical Report, Vol. 114, No. 2, (Apr. 2013), pp. 72-80, ISSN 1214-6994.

[81] Tukek, T.; Yildiz, P.; Atilgan, D.; Tuzcu, V.; Eren, M.; Erk, O.; Demirel, S.; Akkaya, V.; Dilmener, M. \& Korkut, F. (2003). Effect of diurnal variability of heart rate on development of arrhythmia in patients with chronic obstructive pulmonary disease. International Journal of Cardiology, Vol. 88, No. 2-3, (Apr 2003), pp. 199-206, ISSN: 0167-5273.

[82] Waterhouse, J.; Witte, K.; Huser, L.; Nevill, A.; Atkinson, G.; Reilly, T. \& Lemmer, B. (2000). Sensitivity of heart rate and blood pressure to spontaneous activity in transgenic rats. Biological Rhythm Research, Vol. 31, No. 2, (Apr 2000), pp. 146-159, ISSN: 0929-1016.

[83] Wolleben, C.D.; Sanguinetti, M.C. \& Siegl, P.K.S. (1989). Influence of ATP-sensitive potassium channel modulators on ischemia-induced fibrillation in isolated rat hearts. Journal of Molecular and Cellular Cardiology, Vol. 21, No. 8, (Aug 1989), 783-788, ISSN: 0022-2828.

[84] Xu, J.; Wang, L.; Hurt, C.M. \& Pelleg, A. (1994). Endogenous adenosine does not activate ATPsensitive pottasium channels in the hypoxic guinea pig ventricle in vivo. Circulation, Vol. 89, No. 3, (Mar 1994), pp. 1209-1216, ISSN: 1524-4539.

[85] Yamashita, J.; Nomura, M.; Uehara, K.; Nakaya, Y.; Uemura, E.; Iga, A.; Sawa, Y.; Nishikado, A.; Saito, K. \& Ito, S. (2004). Influence of sleep apnea on autonomic nervous activity and QT dispersion in patients with essential hypertension and old myocardial infarction. Journal of Electrocardiology, Vol. 37, No. 1, (Jan 2004), pp. 31-40, doi: 10.1016/j.jelectrocard.2003.10.009 